\title{
BOOK REVIEW: Gube, J., \& Gao, F. (Eds). (2019). Education, Ethnicity and Equity in the Multilingual Asian Context. Singapore: Springer. 286 pp. ISBN: 978- 981-13-3124-4.
}

Erina Iwasaki ${ }^{1}$

Teachers College, Columbia University, USA

This volume edited by Fang Gao and Jan Gube of the Education University of Hong Kong is a collection of research studies that critically address issues of equity and education in the Asian context from the standpoint of "ethnic minorities," which are defined as "people who are different from the majority in the ethnocultural background" (p. 2). While most of the chapters (seven out of 15) are focused on the Hong Kong context, it is a timely and muchneeded book insofar as it uncovers the existing diversity and complexity of a region that may often be perceived as a homogenous and thriving modern society, when it is also a region affected by globalization, migration, and vestiges of colonial/imperial histories. By looking at equity and education from the viewpoints and the lived experiences of "ethnic minority people," this book sheds light on issues of power and uncovers structural injustices such as "racism, societal and educational inequalities, and cross-generational poverty" (p. 2) in this region. The book includes articles from other parts of Asia such as Cambodia, China, Pakistan, Korea, Russia, and Central Asia, expanding our outlook on issues of equity and education to other Asian contexts.

The book is organized into three parts. Part 1 deals with language policies and practices, particularly on the varied ethnolinguistic practices of South Asian individuals in Hong Kong, where it is required to be proficient in English, Cantonese and Mandarin (Byrom et al, 2019, p. 15-32; Thapa, 2019, p. 33-50). It also presents the societal impact of language policies that are more or less inclusive of minoritized languages such as Miao in China or Indigenous languages like Tampuen and Kreung in Cambodia (Shan et al, 2019; Wong \& Benson, 2019). Part 2 delves into issues of racialized discourses, diversities and identities on the identity formation of "ethnic minorities" as manifested in their lived experiences when navigating policies and institutions that are not inclusive of their communities. Indeed, the articles in this section show that despite Hong Kong's multicultural appearance and its discourse on diversity, "ethnic minorities" are often tokenized into "idealized" communities by the Chinese ethnic majority (Fleming, p. 89-104), or in other instances, their cultural differences are racialized so that they feel othered instead of accepted (Gube \& Burkholder, p. 105-122). Another article addresses the complexities of citizenship of "ethnic minorities" in

\footnotetext{
${ }^{1}$ Correspondence: ei2232@tc.columbia.edu
} 
Hong Kong after Hong Kong's handover to China in 1997, which does not provide certain ethnicities citizenship, prohibiting them from taking on any political or highly placed administrative position, when they feel they belong in Hong Kong and have lived there for generations (Ng \& Kennedy, p. 123-140). The last article of this part documents the lived experiences and forgotten lives of Russian Koreans in Soviet Russia, and how they have continued to transmit Korean culture and language to their descendants as well as to Russians and other groups (i.e. Uyghurs) living in their communities.

Finally, the last part of this book is entitled "Educational equity and equality provisions and interventions." The chapters in this section document what can be done or has been done through research focused on pedagogical (Soto, p. 197-214), curricular (Muhammad \& Brett, p. 235-254), policy (Kumar Bhowmik, p. 179-196; Gao \&Tsang, p. 215234), and historical (Park \& Balitskaya, p. 255-274) interventions and measures, uncovering the underlying issues that hinder the realization of educational equity and equality in schools.

Methodologically speaking, the research presented in this book is mostly qualitative in nature, using ethnographic studies, discourse analysis, historiography and interviews. While these studies illuminate how pervasive issues of race, ethnicity, and class profoundly affect the lives of those who are marginalized, the book does not touch upon on how widespread these issues are. However, there are two quantitative studies, one that uncovers the existing diversity and discrimination experienced by migrants in South Korea, and the other that analyzes parental involvement in relation to university enrollment amongst ethnic Korean students in China (Seong, p.161-175; Gao \& Tsang, p. 215-233). All of the methods used reveal what these minoritized groups are struggling with, and most studies suggest further policy or social interventions to address these phenomena of marginalization. Another positive point worth noting is that most chapters in this book take into account the languages in which they conduct their research, and whether or not they have used an interpreter in their investigations. Such attention is very much appreciated, as it shows that the researchers have taken the linguistic practices of the communities seriously, contributing to the rigor of research in multilingual settings.

On another note, one may wish to problematize the term "ethnic minority" and the editors' definition. Despite the commitment of this book to illuminate problems of inequity in education, we may wish to discuss whether it is an appropriate term to use indiscriminately across contexts, even if it is commonly used in Hong Kong. The authors acknowledge that "ethnic minorities" may have a different usage and meaning in contexts outside of Hong Kong, using other terms such as "minoritized," "ethnolinguistic" or "non-dominant" when discussing such communities would avoid reproducing further othering language (e.g. Kosonen 2010). Indeed, the ethnolinguistic communities that the studies refer to are not always numerical minorities, and one must remember that all people have ethnicity.

In conclusion, this book succeeds in shedding light on "the educational experiences of the different ethnic minority groups in multilingual contexts in Asia" (p. 1) in many different ways, their interwoven, complex identities and practices affirming the depth and knowledge of the groups that some look down upon. It also presents a critical perspective on education in Asia that any researcher or educator interested in social justice would find interesting to read. It would be worth exploring a similar angle of research in other parts of Asia, namely Southeast Asian contexts with transitional democracies and economies, which also host a multitude of ethnicities and languages. Research of this type in this region may provide new perspectives on issues of education, equity, and ethnicity. All in all, this book is highly recommended as a source of inspiration to anyone aiming to do research on education, ethnicity, and equity in multilingual settings. 


\title{
References
}

Kosonen, K. (2010). Ethnolinguistic minorities and non-dominant languages in mainland Southeast Asian language-in-education policies (pp. 73-88), in M. A. Geo-JaJa \& S. Majhanovich (Eds.), Education, Language, and Economics: Growing National and Global Dilemmas. Rotterdam: Sense.

\begin{abstract}
About the Author
Erina Iwasaki is a doctoral fellow in International and Comparative Education, specialized in philosophy at Teachers College Columbia University. Her research interests lie in language in education policies, multilingual education advocacy and practices primarily in the West African and South East Asian contexts. A multilingual herself, she is fluent in French, English, Japanese, Spanish, and Burmese and is working on other also a curriculum advisor to a multilingual school in Myanmar. Her dissertation topic is on bilingual education advocacy in Senegal, and she is currently working on her Senegalese languages.
\end{abstract}

